\title{
DESARROLLO PROFESIONAL DOCENTE EN ESCUELAS DE EDUCACIÓN PRIMARIA: UN ESTUDIO DIAGNÓSTICO DESDE UNA PERSPECTIVA INTERNACIONAL
}

\section{PRIMARY TEACHER PROFESSIONAL DEVELOPMENT: A DIAGNOSIS STUDY FROM AN INTERNATIONAL PERSPECTIVE}

Josemaría Elizondo García Katherina Edith Gallardo Córdova

Maestría en Administración de Instituciones Educativas (Instituto Tecnológico y de Estudios Superiores de Monterrey, ITESM). Estudiante doctoral del Programa en Innovación Educativa, Escuela de Humanidades y Educación (Instituto Tecnológico y de Estudios Superiores de Monterrey, ITESM).

Correo electrónico: [josemaria.elizondo@itesm.mx].

Doctorado en Innovación Educativa (Instituto Tecnológico y de Estudios Superiores de Monterrey, ITESM). Profesora investigadora Nivel SNI: 1. Principal línea de investigación: evaluación del aprendizaje.

Correo electrónico: [katherina.gallardo@itesm.mx]. 


\section{RESUMEN}

Para promover la mejora de la capacitación y el desarrollo profesional docente es indispensable saber las condiciones escolares en las que éstas se llevan a cabo. La presente investigación se propuso conocer las condiciones de desarrollo profesional de los docentes de educación primaria en Colima, México, en comparación con otros docentes a nivel internacional. Se aplicaron cuestionarios para 842 docentes de educación pública, en escuelas primarias del estado de Colima, centrados en las variables de formación profesional, inducción, asesoría y evaluación docente. Desde una perspectiva internacional, los resultados muestran que el área de capacitación y formación profesional es más atendido en México; sin embargo, los aspectos de inducción, asesoría y evaluación presentan áreas de oportunidad que conviene atender. Se aprecia la necesidad apremiante de revisar la oferta de capacitación docente para que se adapte al contexto cultural y a los requerimientos particulares de los docentes.

Palabras clave: formación docente, actualización docente, evaluación docente, educación básica, diagnóstico educativo.

\section{ABSTRACT}

Training and professional development of teachers are strategies that education systems must strengthen in order to face the new educational challenges. To promote their improvement it is necessary to know the schools and teachers conditions in which these are implemented. A descriptive research about some aspects related to the professional development of teachers in Colima, Mexico is presented, in comparison with other teachers at an international scale. Questionnaires based on TALIS were applied to 842 teachers of public elementary schools focused on the variables of professional training, induction, mentoring and teacher assessment. Considering an international perspective, the results show professional development and training are more attended in Mexico. However, induction, mentoring 
and assessment are some areas of opportunity for this country. The urgent need to revise the offer of teacher training is appreciated, so this can be adapted to the cultural context and the particular needs of teachers.

Key words: teacher education, evaluation, primary education.

\section{INTRODUCCIÓN}

Las exigencias derivadas de los cambios sociales, en los últimos años - con motivo del surgimiento de nuevas demandas en la llamada sociedad del conocimiento-, han afectado a una serie de estructuras e instituciones (Bell, 1976; Drucker, 1969). La escuela no es la excepción. Hoy en día, los docentes se enfrentan con mayor frecuencia a diversos retos relacionados con la multiculturalidad, la integración de las Tecnologías de la Información y la Comunicación (TIC), el diseño de nuevas formas para evaluar el aprendizaje, e inclusive - en un escenario más especializado-, con procesos de adaptación e integración de niños con discapacidades al aula regular (Schleicher, 2009; Villegas-Reimers, 2003).

Por lo anterior, la capacitación y el desarrollo profesional de los docentes son estrategias que los sistemas educativos deben fortalecer con el fin de enfrentar los nuevos desafíos educativos. Joyce y Showers (citados por Day, 1999) definen el desarrollo profesional docente como todas las experiencias de aprendizaje con el propósito de ejercer un beneficio directo al docente en ejercicio, que contribuyan a desarrollar o perfeccionar sus competencias docentes. Con este tipo de apoyo, se espera que el docente desarrolle una serie de conocimientos, habilidades, incluso inteligencia emocional, como aspectos esenciales para ejercer su profesión apropiadamente.

De hecho, es obligatorio que los sistemas educativos ofrezcan a sus docentes las oportunidades requeridas para alcanzar un óptimo desarrollo profesional, y de esta manera, mantener un alto nivel de enseñanza que derive en una calidad educativa deseable (Mendoza y Roux, 2016). El desarrollo profesional resulta efectivo siempre 
y cuando se conjuguen en su ejecución procesos de entrenamiento, práctica y retroalimentación, así como la asignación de tiempo suficiente para su ejercicio y de una adecuada estrategia de seguimiento (BID, 2011; OCDE, 2004; OCDE 2009a; Villegas-Reimers, 2003).

\section{EL DESARROLLO PROFESIONAL DOCENTE COMO TEMA MUNDIAL}

El desarrollo profesional docente es un tema de importancia mundial. Tal como lo advierte Villegas-Reimers (2003), se ha vuelto un elemento clave para que crear nuevas reformas educativas y enfrentar los retos que el cambio presenta. Así, este concepto es estudiado y analizado constantemente por organismos globales como la Organización de las Naciones Unidas para la Educación, la Ciencia y la Cultura (UNESCO), la Organización para la Cooperación y el Desarrollo Económicos (OCDE), y el Banco Interamericano de Desarrollo (BID), entre los principales organismos, como un elemento clave que orienta y configura el desarrollo social, económico y cultural de una nación (Barrera-Pedemonte, 2016; Villegas-Reimers, 2003; BID, 2011).

Cabe destacar que este tema — el desarrollo profesional docenteha traspasado los muros escolares, toda vez que existe una problemática en torno suyo relacionada con intereses políticos y con tediosos asuntos burocráticos que, en muchas ocasiones, perjudican el avance y fortalecimiento de las competencias docentes. Según Vezub (2007), los desafíos que enfrentan los sistemas educativos, gobiernos y tomadores de decisiones sobre el rumbo del desarrollo docente son vastos. En América Latina, la urgencia se centra principalmente en redefinir el papel de las instituciones a cargo de la formación docente y reformular el valor de acumular horas de formación, cayendo así en el «credencialismo» —atendiendo normativas político-administrativas que así lo demandan-, ya que esto aleja a los docentes de un genuino interés por desarrollar competencias docentes para ejercer mejor su labor en el aula.

Los desafíos anteriormente expuestos requieren de estrategias adecuadas para comprender los problemas que existen en el mundo 
alrededor del tema de desarrollo docente. Resulta imprescindible contar con herramientas que permitan recolectar información para advertir las distintas problemáticas y proponer cambios en función de la realidad de cada nación. En aras de atender y coordinar las políticas económicas y sociales a nivel mundial, la OCDE ha desarrollado, a lo largo de varios años, estrategias para documentar cuáles acciones llevan a cabo los diferentes sistemas educativos para la exitosa preparación académica de sus docentes. Así, esta organización realizó la Encuesta Internacional sobre Docencia y Aprendizaje (TALIS, por sus siglas en inglés), proporcionando información válida, oportuna y comparable para ayudar a los tomadores de decisiones de los países participantes a definir políticas que lleven a los docentes a ejercer procesos de enseñanza de alta calidad.

TALIS (OCDE, 2009b) coadyuva a conocer qué tan bien se han detectado los requerimientos de los docentes, observando principalmente: la frecuencia en que se ofrece el desarrollo profesional y el tipo de desarrollo profesional asumido; el apoyo prestado para el desarrollo profesional y los obstáculos encontrados; así como los tipos de necesidades de desarrollo que enfrentan los docentes. Este instrumento ha sido aplicado en diferentes países del mundo; para el caso de América Latina, hasta la fecha sólo se ha aplicado en México y Chile. En el presente artículo, los investigadores se centrarán en los resultados que corresponden a México.

\section{PERSPECTIVA SOBRE EL DESARROLLO DOCENTE EN MÉXICO, A PARTIR DE LA APLICACIÓN DEL TALIS}

El estudio internacional TALIS se ha aplicado en México en dos ocasiones: en 2008 y en 2013, con el objetivo de ser comparado con el resto de los países participantes. En 2008, México participó con una muestra de 191 directores y 3,368 docentes de educación secundaria, nivel educativo para el que se hizo este estudio internacional. En 2013, además de realizarse el estudio en escuelas secundarias (nuestro país participó con una muestra de 187 directores y 3,571 docentes), el ejercicio también se aplicó en escuelas 
primarias (183 directores y 1,445 docentes) y de educación media superior (190 directores y 2,940 docentes) (Backhoff y Pérez, 2015).

Adicionalmente, en ambas ocasiones, México realizó una versión local de TALIS para proveer información con mayor nivel de desagregación a escala estatal, es decir, para tener representatividad por entidad federativa, de forma que pudieran hacerse inferencias sobre cada estado. En 2008, la versión local de TALIS para México se aplicó a nivel secundaria en 31 entidades federativas. En 2013, este estudio se realizó en seis entidades federativas que lo solicitaron, aplicando en los niveles de primaria, secundaria y preparatoria.

Sin duda, los resultados del estudio TALIS realizado en México arrojan una serie de datos que podrían ayudar a una mejor orientación de la formación y el desarrollo profesionales; no obstante, al pretender aplicar medidas para el cambio en una entidad federativa y en un nivel educativo específico (como educación primaria), dicha modificación tendría que hacerse con reservas. Sería recomendable que tal compromiso de cambio y mejora partiera de datos más apegados a cada realidad estatal.

Por este motivo, se decidió realizar la aplicación de TALIS en Colima, como uno de los estados en donde el hecho de contar con resultados ceñidos a su realidad concreta, podría llevar a los tomadores de decisiones a ajustar mejor las políticas de cambio y superación del cuerpo docente. Por lo anterior, se planteó la siguiente pregunta de investigación: ¿cuáles condiciones de desarrollo profesional tienen los docentes de educación primaria en el estado de Colima, para ejercer su labor educativa en comparación con otros docentes a nivel internacional, específicamente aquellos que laboran en países pertenecientes al grupo de la OCDE?

\section{MÉTODO}

\section{- Diseño}

Se realizó un estudio descriptivo, dado que el interés principal de esta investigación fue especificar las propiedades, las características y 
los perfiles de los docentes que laboran en educación primaria del estado de Colima. Así, este diseño permitió recolectar, medir y evaluar datos sobre diversos conceptos y variables conjugados en el desarrollo profesional docente, desde un enfoque cuantitativo (Hernández, Fernández-Collado y Baptista, 2010).

\section{- Contexto}

Colima es una entidad federativa ubicada en el oeste de México. Es uno de los estados con menor territorio y población del país. Cuenta con 10 municipios habitados por un total de 723,455 personas. Las estadísticas señalan que, en educación primaria (nivel en el que se trabajó esta investigación), el estado cuenta con 496 planteles, a los que asisten 80,488 estudiantes. Un total de 6,132 docentes de educación primaria laboran en estos recintos. El rendimiento académico a nivel de educación primaria en pruebas censales (como ENLACE 2013) señala que los estudiantes se encuentran por debajo del porcentaje promedio en los temas evaluados, en torno de los resultados nacionales (SEP, 2014).

\section{- Participantes}

El total de participantes en este estudio fue de 842 docentes de nivel primaria, lo cual excede la cantidad exigida para una muestra de estudio con un error de 5\%. La selección de estos profesores se basó en dos criterios principalmente: 1 ) tener representatividad de todos los municipios, y 2) haber corroborado a priori que, de preferencia, los centros educativos tuvieran un aula de medios para poder contestar de forma electrónica el instrumento adaptado del TALIS. Se invitó a los docentes de 106 escuelas (de un total de 496) a contestar el instrumento; con base en ello, se estima que en promedio, por escuela, alrededor de $70 \%$ de profesores, por plantel, respondió la encuesta. Como características generales de los docentes se identificó que $73.3 \%$ corresponde al sexo femenino y $26.7 \%$ representa a los hombres. El promedio de edad de los docentes es de 36.4 años. Cabe resaltar que $60.3 \%$ es menor de 37 años, y $20 \%$ corresponde a un sector de mayores de 48 años.

Con base en resultados, y de acuerdo con sus años de experiencia, puede afirmarse que el cuerpo de docentes de Colima (a lo largo de 
sus 10 municipios), es joven en su mayoría, toda vez que el $32.66 \%$ cuenta hasta con cinco años de experiencia; el 22.68\% cuenta con hasta 10 años de experiencia. Un porcentaje menor (10\%) se encuentra concentrado en 26 a 30 años de experiencia. Además, este grupo sostiene un alto nivel de movilidad (Tablas 1 y 2 - Apéndices).

\section{- Instrumentos}

El instrumento TALIS, creado por la OCDE (2013), utiliza la técnica de encuesta en forma de cuestionario y se realizan las mismas preguntas a toda la muestra (Giroux y Tremblay, 2004). Se sabe que TALIS mide las creencias, actitudes y prácticas que los profesores y directores reportan de sí mismos. El desarrollo de estas creencias, actitudes y prácticas es influenciado por características personales, pero también por antecedentes culturales y por el sistema escolar (Van de Vijver y Leung, 1997, citado por OCDE, 2014). Estas influencias pueden producir diferentes niveles de aprobación o de frecuencia en las respuestas del cuestionario, lo que a su vez puede limitar la comparación de los resultados.

Para el presente estudio, se utilizó una adaptación del instrumento original para profesores. Esta adaptación se denominó Cuestionario para DOCENTES - CONACyT/INEE - Colima 2015. Las categorías que comprende este estudio son: a) formación profesional; $b$ ) desarrollo profesional (integra: inducción y asesoría; capacitación y formación continua; trabajo colegiado), y c) percepción sobre la evaluación docente. La Tabla 3 incluye la definición de cada categoría: 
Tabla 3. Definición de las categorías que integran la evaluación de desarrollo profesional docente en el instrumento CONACYT/INEE - Cuestionario para DOCENTES - Colima 2015.

\begin{tabular}{lll}
\hline Categoria & Subcategorias & Definición \\
\hline $\begin{array}{l}\text { Formación } \\
\text { profesional }\end{array}$ & & $\begin{array}{l}\text { Estudios formales en preparación al } \\
\text { ejercicio de la profesión docente. }\end{array}$ \\
$\begin{array}{l}\text { Desarrollo } \\
\text { profesional }\end{array}$ & $\begin{array}{l}\text { Inducción } \\
\text { asesoria } \\
\text { Capacitación y y y } \\
\text { formación } \\
\text { continua }\end{array}$ & $\begin{array}{l}\text { Actividades dedicadas a los docentes } \\
\text { de nuevo ingreso. } \\
\text { desarrollar las habilidades y el } \\
\text { conocimiento profesionales de los } \\
\text { docentes. }\end{array}$ \\
& $\begin{array}{l}\text { Trabajo } \\
\text { colegiado }\end{array}$ & $\begin{array}{l}\text { Actividades de colaboración entre } \\
\text { docentes. }\end{array}$ \\
$\begin{array}{l}\text { Percepción } \\
\text { sobre } \\
\text { evaluación } \\
\text { docente }\end{array}$ & $\begin{array}{l}\text { Revisión y retroalimentación al } \\
\text { trabajo del profesor, ya sea por parte } \\
\text { del director, de un inspector externo o } \\
\text { por sus colegas. }\end{array}$ \\
\hline
\end{tabular}

Fuente: Elaboración propia.

Así, de las 49 preguntas que contiene el instrumento original, la adaptación anteriormente mencionada consideró 3; sin embargo, se estimó que 19 de ellas aportarían información irrelevante, dada la naturaleza de la organización del número de horas de trabajo y distribución previa de responsabilidades laborales.

\section{- Procedimientos}

El instrumento se alojó en un medio electrónico que permitiría la construcción de una base de datos en formato digital para su mejor manejo y su óptimo tratamiento. La aplicación del instrumento demandó, en primera instancia, la petición formal a las autoridades educativas. 
Así, se tuvo acceso a las escuelas y con ello se mantuvo comunicación oral o escrita (vía electrónica) con los docentes. La invitación para contestar el instrumento se realizó principalmente a través del director escolar como primer interlocutor $\mathrm{y}$, posteriormente, con los docentes de manera directa.

Se analizaron los resultados con base en estadísticos descriptivos de la percepción de los docentes. Para este análisis, conviene señalar una consideración, que mencionan Backhoff y Pérez Morán (2015), respecto de la interpretación de los resultados de TALIS: debido a que se trata de una encuesta transversal, no es posible inferir causalidad entre sus variables, por ello conviene que, para su interpretación, se tomen en cuenta consideraciones teóricas y evidencias empíricas sólidamente fundamentadas. Por tal motivo, después de presentar los resultados del análisis descriptivo, éstos se discuten con base en los resultados de TALIS 2013 — tanto a nivel nacional como internacional—, presentados por la OCDE en la sección Teaching and Learning International Survey (2013), y por el Instituto Nacional para la Evaluación de la Educación (INEE); tanto el reporte de resultados TALIS 2013 para México (Backhoff y Pérez-Morán, 2015) como el Informe de Docentes en México (INEE, 2015), los cuales ayudan a dar mayor sustento a los resultados obtenidos en el presente estudio.

\section{- Resultados}

Se presentan los resultados de la aplicación del instrumento a docentes con base en las tres categorías anteriormente descritas: 1) formación profesional; 2) desarrollo profesional (integra: inducción y asesoría; capacitación y formación continua; y trabajo colegiado), y 3) percepción sobre la evaluación docente.

\section{Formación profesional}

Los resultados revelan que $91.2 \%$ cursó la escuela normal, la licenciatura y / o la maestría. El 7.7\% señaló haber estudiado sólo el bachillerato, diploma de profesional técnico o como egresado de la escuela normal (anterior a 1983), mientras $0.7 \%$ dijo contar con doctorado, y $91.3 \%$ señaló tener una formación profesional en el área de la educación. 
Con base en el 100\% que cursó una carrera en educación o un programa de educación docente, se sabe que $70.74 \%$ estudió los contenidos que ahora imparte en el aula, durante sus estudios superiores; $21.19 \%$ afirmó que estudió los contenidos, que ahora imparte, de forma parcial durante sus estudios profesionales, y $8.06 \%$ declaró no haber estudiado en la carrera los contenidos que ahora imparte.

En torno a las bases pedagógicas para la impartición de las materias, $74.12 \%$ señaló que su formación incluyó dichas bases; $23.01 \%$ indicó haberlas estudiado en relación con algunas materias que imparte, y 2.85\% afirmó que no se incluyeron estas bases en su carrera. Sin embargo, al momento de preguntar sobre las prácticas profesionales previas al ejercicio docente, $76.98 \%$ confirmó haberlas realizado en las materias que ahora imparte, mientras que $19.76 \%$ señaló haberlas cumplido de forma parcial. Sólo 3.25\% declaró no haber hecho prácticas profesionales en las materias que imparte actualmente, y $75.4 \%$ afirmó no haber participado como profesional en otras funciones ajenas al campo educativo.

\section{Desarrollo profesional}

\subsection{Inducción y asesoría para docentes}

Los resultados muestran que $36.8 \%$ participó en un programa de inducción para docentes de nuevo ingreso, 25.8\% afirmó haber recibido inducción informal para docentes de nuevo ingreso, y 29.8\% informó haber participado en alguna inducción general o administrativa para docentes de nuevo ingreso. Por otra parte, respecto de la asesoría que se brinda a los profesores, $58.1 \%$ señaló que reciben asesoría técnico-pedagógica en su escuela, y $12.4 \%$ indicó asesorar a uno o más profesores.

\subsection{Capacitación y formación continua}

A partir de los resultados obtenidos, 20\% de los encuestados afirmó haber participado en un programa de cualificación (por ejemplo, programa para obtener un grado académico) como actividad de desarrollo 
profesional, durante los últimos 12 meses; 36.3\% declaró haberse integrado en una red de docentes dedicada específicamente al desarrollo profesional, y $38.7 \%$ aseguró haberse involucrado en asesoría, observación o consejería de docentes como una actividad formal de la escuela.

Durante los últimos 12 meses, $87.6 \%$ reportó haber participado en cursos o talleres; cabe destacar que, en promedio, los docentes se involucran 21 días al año en este tipo de actividades. Respecto de la participación en congresos o seminarios sobre educación, $26.4 \%$ aseguró haber colaborado en este tipo de actividad. Asimismo, 21\% participó en visitas de observación a otras escuelas; en ambas actividades el promedio de duración es de dos días.

En ese orden de ideas, $15.3 \%$ de los docentes entrevistados afirmó haber intervenido en visitas de observación a organizaciones públicas, privadas o no gubernamentales; en promedio, los profesores participan un día en este tipo de actividad. En torno de los cursos de formación en el servicio de organizaciones públicas, privadas, o no gubernamentales, $25.7 \%$ manifestó haber participado en este tipo de actividad, a la cual le dedican cinco días en promedio. La figura 1 muestra una mejor visualización de estos resultados.

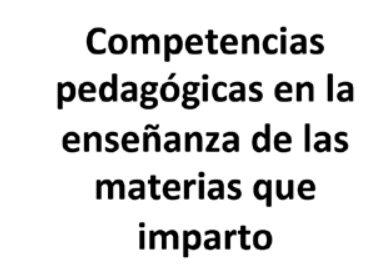

Ninguno Escaso $=$ Moderado

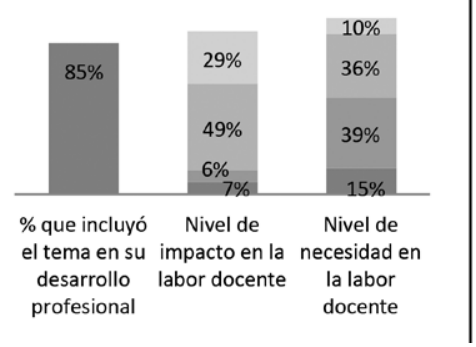

\section{Prácticas de evaluación del estudiante}

Ninguno $=$ Escaso $=$ Moderado $\amalg$ Fuerte

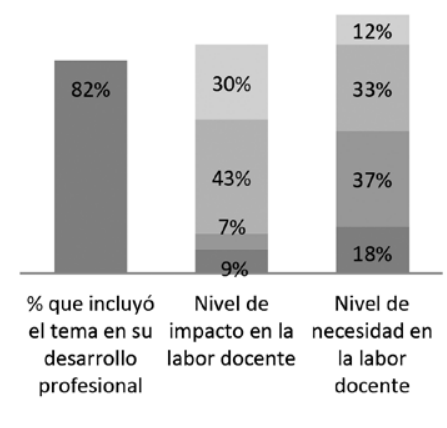




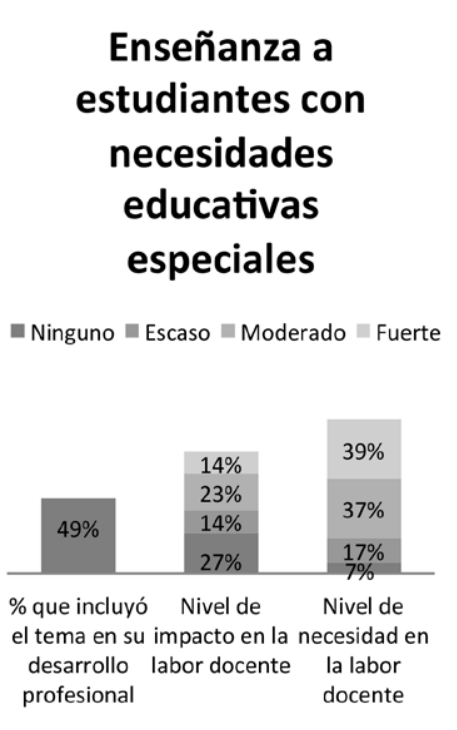

\section{Enseñanza en un entorno multicultural o multilingüe}

Einguno $=$ Escaso $=$ Moderado $=$ Fuerte

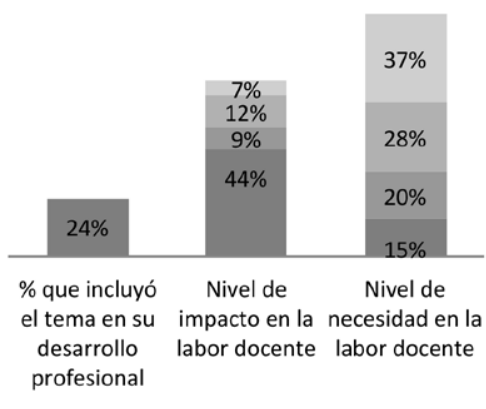

La figura anterior, resalta los resultados más relevantes respecto de la percepción de los docentes sobre el grado de impacto y el nivel de necesidad con relación a los temas que han conformado el portafolio de capacitación y formación continua (para ver más detalles, consultar la tabla 4 de los Apéndices).

En la investigación que nos ocupa se preguntó a los docentes acerca de los aspectos que obstaculizan su desarrollo profesional. Conviene destacar que aunque éstos consideran contar con los requisitos necesarios para participar en este tipo de actividades, la mayoría también asegura que no existe un plan de incentivos adecuados para involucrarse de manera más dinámica en ellas; asimismo, $44.2 \%$ señaló estar de acuerdo o totalmente de acuerdo en que no se ofrece desarrollo profesional relevante; mientras $40.7 \%$ consideró que éste resulta muy costoso; finalmente, $38.2 \%$ señaló que no se adecua a su horario laboral, contra $35.7 \%$ que reportó no disponer de tiempo para capacitarse debido a sus responsabilidades familiares, y $33.4 \%$ fue enfático en señalar que falta apoyo por parte de sus superiores. 


\subsection{Trabajo colegiado}

El trabajo colegiado se vislumbra como otro elemento que podría favorecer el desarrollo de competencias docentes. Por tal motivo se realizaron algunas preguntas acerca de cómo éste favorece al desarrollo profesional. Se cuestionó a los docentes sobre la frecuencia en que realizan algunas actividades colaborativas con otros colegas en aras de seguir desarrollando o perfeccionando sus competencias docentes. Al preguntarles si participan en actividades colaborativas de aprendizaje profesional, $36.1 \%$ indicó realizar esta actividad entre una y tres veces al mes, mientras que $23.5 \%$ afirmó llevar a cabo esta actividad entre cinco y 10 veces al año.

Con referencia a la pregunta acerca de impartir la clase conjuntamente con otros docentes, se destaca la respuesta (con 55.2\%) que nunca se realiza este tipo de actividad, mientras $15.8 \%$ indicó que al menos una vez al año recurre a esta práctica de apoyo. Se les cuestionó la frecuencia con la que observan y retroalimentan las clases de otros docentes; al respecto, $54.5 \%$ señaló nunca realizar esta actividad, mientras que $17.8 \%$ indicó practicar esta actividad una vez al año.

Adicionalmente, se cuestionó a los docentes acerca de su participación en conversaciones sobre el desempeño de los alumnos. Aquí destaca que $35.6 \%$ aceptó haber realizado esta actividad por lo menos una vez a la semana, mientras que $31 \%$ afirmó hacerlo entre una y tres veces al mes. Por último, ante la pregunta de trabajar con otros colegas para establecer estándares comunes de evaluación sobre el desempeño de los estudiantes, $31.7 \%$ dijo trabajar de forma colegiada sobre este tema, entre una y tres veces al mes, contra $21.1 \%$ que manifestó haber trabajado bajo este esquema entre cinco y 10 veces al año.

\section{Percepción sobre la evaluación docente}

El apartado de evaluación docente consiste en la revisión y retroalimentación del trabajo docente, ya sea por parte del director, alguna otra autoridad o por parte de sus colegas. Para ello, se preguntó a los docentes por las figuras que, de algún modo, se involucran en su evaluación y retroalimentación; en cuanto a la observación directa de 
la enseñanza en el aula, 85.7\% señaló que reciben retroalimentación a partir de esta actividad, en tanto $70 \%$ indicó que el director realiza esta actividad, mientras que $18.5 \%$ manifestó que el proceso de observación está a cargo de asesores técnico-pedagógicos; finalmente, $14.3 \%$ reveló que nunca ha sido observado durante el proceso de enseñanza-aprendizaje en el aula.

En relación con el análisis de los resultados de evaluación de los estudiantes, 93.1\% de los docentes encuestados afirmó recibir retroalimentación a partir de esta actividad, mientras $66 \%$ indicó que el director retroalimenta su desempeño docente considerando el rendimiento escolar de sus alumnos, 15\% dijo recibir esta retroalimentación por parte de sus asesores. En este rubro destaca la ausencia de este factor en $6.9 \%$.

Adicionalmente, se preguntó a los docentes sobre su percepción en cuanto al valor de la evaluación en la mejora de los procesos de enseñanza. Al integrar los porcentajes «de acuerdo» y «totalmente de acuerdo» versus en «desacuerdo» $\mathrm{y}$ «totalmente en desacuerdo», se observaron los siguientes resultados:

Se evidenció que $45.3 \%$ afirmó que los docentes con mejor desempeño académico reciben mayor reconocimiento, mientras que $54.7 \%$ rechazó esta relación. En este mismo rubro, se les preguntó si la evaluación y la retroalimentación sobre el desempeño docente inciden en la enseñanza, como respuesta se obtuvo que 58.3\% afirmó estar de acuerdo; respecto de la pregunta si se brinda retroalimentación con base en una exhaustiva evaluación de su enseñanza, $61.7 \%$ indicó ausencia de un proceso de evaluación exhaustiva, mientras que $38.3 \%$ señaló que dicho proceso sí se lleva a cabo.

Conviene asimismo destacar que $67 \%$ especificó que una autoridad o un colega revisan estrategias o actividades para fortalecer las debilidades detectadas en la enseñanza, mientras que 33\% rechazó esta afirmación. En torno al hecho de asignar un asesor para apoyar al docente en la mejora de sus prácticas de enseñanza, $51.4 \%$ se decantó de manera positiva por esta opción, mientras que $48.6 \%$ indicó que desde su experiencia esto no sucede; por último, $9 \%$ destacó que no existe un plan de desarrollo profesional para mejorar el desempeño. 


\section{ANÁLISIS Y DISCUSIÓN DE RESULTADOS}

A continuación se analizan los resultados obtenidos en el estado de Colima, y se discuten en comparación con aquéllos obtenidos a nivel internacional. Para presentar los resultados internacionales se consideran las mismas categorías de la encuesta TALIS 2013, que fue aplicada para nivel primaria en México, Finlandia, Noruega, Dinamarca, Bélgica y Polonia.

\section{Formación profesional}

El nivel de formación profesional de los docentes de primaria - pertenecientes al estado de Colima- ubicó como primer lugar que 91.2\% cuenta con una preparación a nivel licenciatura y/o maestría, porcentaje equiparable al reportado por países como Finlandia, Dinamarca, Noruega y Polonia; no obstante, si se analiza el porcentaje total de México en este rubro, podrá apreciarse que éste sólo alcanzó 79.5\%. En este escenario, en cuanto a la preparación de sus profesores, se advierte que Colima está al nivel de los países mejor evaluados que participan en la encuesta TALIS, a nivel primaria.

\section{Desarrollo profesional}

- Inducción y asesoría a docentes

Respecto de la asesoría que se brinda a los profesores, mientras que en Colima 58.1\% afirmó recibir asesoría técnico-pedagógica, en México (a nivel país), 21.7\% señaló que recibe este tipo de asesoría. En promedio, a nivel internacional, $8.2 \%$ indicó recibir mentoría o asesoría de otros docentes. De vuelta en Colima, 12.4\% aceptó haber asesorado a uno o más profesores, y en México (es decir, a nivel nacional), 7.8\% reportó que se participa de esta actividad, mientras que a nivel internacional 8.9\% realizó este tipo de asesoría. Se infiere que la diferencia de porcentaje de Colima y México, en torno del nivel internacional, pudiera deberse al factor de que se cuenta con un asesor técnico pedagógico dentro de los agentes de acción en el sistema educativo. 
- Capacitación y formación continua

Sobre el desarrollo profesional docente, se evidencia que los dos temas que aparentemente requieren de una mayor capacitación en Colima son: a) la enseñanza en un entorno multicultural o multilingüe ( $36.8 \%$ indicó tener una necesidad alta) y $b$ ) la enseñanza a estudiantes con requerimientos educativos especiales (39.4\% tiene una necesidad alta). Estos resultados se asemejan a los presentados por la OCDE para México: 39.3 y $41.6 \%$, respectivamente, declararon padecer una gran carencia en ambas temáticas. Cabe apuntar que estas dos mismas temáticas fueron también las que, a nivel internacional, se manifestaron como de mayor urgencia, con 12.4 y $22.2 \%$, respectivamente; tanto en Colima como en México, un mayor porcentaje de docentes advirtió su necesidad de capacitación.

- Trabajo colegiado

Al comparar los resultados de Colima - en contraposición con lo reportado en los resultados de TALIS 2013-, se derivan los siguientes datos:

Con respecto a la participación en actividades colaborativas de aprendizaje profesional, los docentes de Colima que reportaron nunca realizar esta actividad representan un $7.1 \%$, por encima de la media de México que respondió ante este cuestionamiento con $4.7 \%$. En contraposición, los países de la OCDE alcanzaron en este rubro, en promedio, 17.4\%. Lo anterior indica que la mayoría de docentes, tanto de Colima como de México, sí participan en mayor medida en actividades colaborativas de aprendizaje, con relación a otros países.

En relación con impartir la clase con otros docentes, Colima informó que nunca lo hace $(55.20 \%)$, mientras en ese mismo rubro, México reportó $9 \%$. En contraposición con otros países, el promedio de que nunca se realiza esta actividad, se estimó en $20.10 \%$, resultado que muestra la gran diferencia nacional e internacional en las prácticas de trabajo de enseñanza conjunta. Se puede inferir que, en Colima, esta práctica no es vista como una herramienta de trabajo colegiado útil para el desarrollo profesional, mientras que en otros estados —incluso en otros países-, sí se considera una actividad valiosa para este fin. 
Referente a la pregunta de observar y retroalimentar clases de otros docentes, Colima informó - con 54.5\% - que nunca se realiza, resultado similar con México que registró, para esa misma pregunta, 51.3\%. Esto coincide con lo reportado a nivel internacional, toda vez que las estadísticas indicaron que los países del extranjero nunca realizan observación ni retroalimentación de clases de otros docentes en un promedio de $49.3 \%$.

En torno a conversar con otros colegas sobre el rendimiento académico de ciertos estudiantes, Colima reportó que nunca lo hace en $2.2 \%$, en contraste con lo que México informó al respecto: $11.6 \%$. Esta cifra ubica a México como el país donde, en mayor medida, los docentes nunca dialogan sobre el rendimiento académico de ciertos estudiantes. En contraste, los países de la OCDE manifestaron en promedio que nunca realizan esta actividad (3.4\%). Esto lleva a inferir que las prácticas de los docentes de Colima en este rubro se parecen mucho a las de los países de la OCDE, pero no así con las del resto del país.

Al cuestionarles acerca del trabajo con otros docentes para establecer criterios y estándares comunes con el fin de evaluar el desempeño académico de los estudiantes, Colima informó que nunca lo realiza (12.4\%), mientras que en México, esta misma actividad se reporta como nunca realizada, arrojando el dato de $14.1 \%$; a nivel internacional se notificó que esta actividad nunca se efectúa $(8.8 \%)$. Se infiere que esta práctica se realiza mayormente en el resto de los países del estudio.

\section{Percepción sobre la evaluación docente}

En torno a la retroalimentación docente recibida a partir de la observación en el aula, los docentes de Colima reportaron recibir retroalimentación a partir de esta actividad, en un porcentaje alto $(85.7 \%)$, ligeramente mayor al $81.7 \%$ manifestado por los docentes de México; a nivel internacional, se reveló que $77.6 \%$ recibe retroalimentación considerando la observación en el aula. En ese sentido, además de la retroalimentación, se cuestionó a los docentes acerca del análisis de los resultados académicos de los estudiantes; los datos arrojaron que Colima reportó $(93.1 \%$ ) que recibe retroalimentación a partir de estos resultados. En México, los resultados señalan que $80 \%$ recibe 
esta retroalimentación; a nivel internacional, el 64.8\% señaló recibir retroalimentación a partir de las calificaciones de los estudiantes. Los reportes señalados indican que, aparentemente, en México las prácticas de retroalimentación se realizan con mayor frecuencia que en el resto de los países participantes.

\section{CONCLUSIONES}

De acuerdo con los resultados que se presentan a nivel nacional e internacional, se concluye que Colima se acerca al registro internacional en cuanto al porcentaje de docentes que cuentan con el grado de licenciatura o maestría; en el caso de México este porcentaje se muestra menor. Al considerar que los docentes en Colima son una población joven, se vislumbra que estos grados académicos sean una exigencia que se cumple cada vez más para la totalidad de los docentes, tanto en Colima como en el resto de los estados de la República Mexicana.

Sobresale el hecho que, tanto en Colima como en México, los docentes reciben más capacitación, a la vez que existe una mayor participación en actividades colaborativas de aprendizaje profesional. Sin embargo, se identifica que existen temáticas de capacitación que no se han abordado de manera adecuada en el país, a pesar de que los docentes las demandan; incluso las consideran como una alta necesidad. Estas temáticas de capacitación que se reclaman urgentes, son aquéllas relacionadas con los requerimientos educativos especiales, y la enseñanza en un entorno multicultural y multilingüe. Por ende, se aprecia la necesidad apremiante de revisar la oferta de capacitación docente para adaptarla al contexto cultural y a los requerimientos particulares de los docentes.

Se destaca también que en comparación con los demás países participantes, en México, y en mayor número en Colima, los docentes cuentan con asesoría o mentoría de sus pares, en este caso, de asesoría técnico-pedagógica. Por otra parte, los resultados muestran que, tanto en Colima como en México, no se tiene un proceso generalizado para asesorar a los docentes de nuevo ingreso, al menos no formalmente. Contar con un proceso formal de inducción y asesoría para los nuevos docentes permitiría que ellos pudieran resolver más apropiadamente las problemáticas específicas de su contexto escolar. 
Asimismo, los reportes destacan que, en comparación con los resultados a nivel internacional, en Colima los docentes mencionan recibir mayor retroalimentación, tanto a partir de su práctica en el aula como a partir de los resultados académicos de sus alumnos. Se espera que estos procesos se fortalezcan en cuanto a calidad se refiere. En consecuencia, podrá contarse con mejores elementos para guiar la práctica educativa de los docentes.

El presente estudio pretende servir de apoyo para tomar más adecuadas y mejor fundamentadas decisiones para el programa de desarrollo profesional docente. Comprender el ámbito nacional en comparación con el internacional es valioso en tanto se configure el plan de desarrollo que esta entidad requiere, considerando las características de edad, el contexto, los años de experiencia y las funciones propias del sistema educativo.

\section{Limitantes del estudio}

El presente estudio se realizó únicamente en un estado de la República Mexicana: el estado de Colima, por lo tanto, no se pretenden generalizar los resultados para todo México. Sin embargo, la diferencia entre algunos resultados que se muestran para esta región, reflejan la diversidad de condiciones y las características que confluyen en un país como México. De este modo, hacen notar la importancia de que, además de contar con una perspectiva nacional e internacional, dirigir un estudio estatal sobre estas condiciones permite tomar decisiones mejor dirigidas para el desarrollo profesional docente en dicha entidad. 


\title{
APÉNDICES
}

\section{Cuestionario para DOCENTES - CONACyT/INEE - Colima 2015}

\author{
Fondo Sectorial CONACyT/SEP - Instituto Nacional de Evaluación para la Educación (INEE) \\ Cuestionario del DOCENTE \\ INDICACIONES IMPORTANTES:
}

Este cuestionario tiene como objetivo generar información sobre las Escuelas de Educación Básica del estado de Colima. Está integrado por 30 preguntas de opción múltiple y sólo se requieren 15-25 minutos aproximadamente para contestario; toda la información que se recolecte se utilizará de forma confidencial y únicamente para el logro de objetivos en investigación educativa.

Agradecemos su participación voluntaria y compromiso con la mejora de la educación.

Centro de Investigación en Educación

Tecnológico de Monterrey

Fondo Sectorial de Investigación para la Educación

Instituto Nacional para la Evaluación de la Educación

POR FAVOR CONTESTE LAS 30 PREGUNTAS QUE SE PRESENTAN A CONTINUACIÓN:

1) Clave de la escuela

2) Municipio:

Armería

Colima 0

Comala

0

Coquimatlán
Cuauhtémoc
|xtlahuacán

Manzanillo $Q$

Tecomán

Minatitlán 0

Villa de Álvarez 0

3) Grado que imparte:
$1^{\circ}$
$2^{\circ}$
$3^{\circ}$
$4^{\circ}$
$5^{\circ}$
$6^{\circ}$

4) Género

Femenino

Masculino

5) Edad

Años:

6) En su escuela, ¿cuál es su situación laboral actual?

Tiempo completo (más del 90\%) como docente.

() Tiempo parcial (71-90\%) como docente.

Tiempo parcial $(50-70 \%)$ como docente.

0 Tiempo parcial (menos del 50\%) como docente.

7) ¿Cuántos años de experiencia profesional posee en el ámbito educativo? Años trabajando como docente de esta escuela:

Años trabajando como docente (en total):

Años trabajando en otras funciones en educación (sin incluir los años como docente):

Años trabajando en otros empleos fuera del ámbito educativo:

8) ¿Trabaja actualmente como docente de Educación Básica en otra escuela además de esta?

Si 0 No 0

9) ¿Cuál es el grado académico más alto que ha completado?

Bachillerato, Profesional Técnico o Normal anterior a 1983

Técnico Superior

Normal Superior, Licenciatura universitaria o tecnológica, Maestría

() Doctorado

10) ¿Cursó una Licenciatura en Educación o un programa de formación docente?

Si $O$ No 
11) ¿Cuáles de los siguientes elementos se incluyeron en su formación docente?

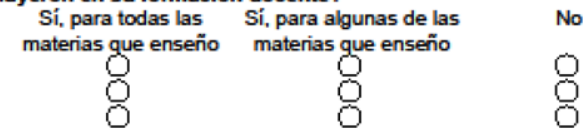

a) Contenidos de las materias que enseño

b) Pedagogía de las materias que enseño

c) Práctica en el aula de las materias que enseño

12) En su labor docente, ¿en qué medida se siente preparado en relación a los siguientes elementos?
a) Contenidos de las materias que enseño
b) Pedagogía de las materias que enseño
c) Práctica en el aula de las materias que enseño

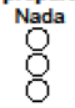<smiles>COc1ccccc1</smiles>
0
Muy bien

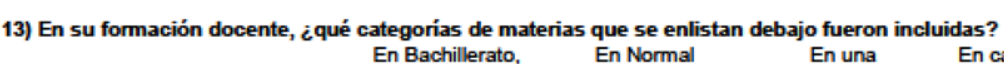
$\begin{array}{cc}\text { En Bachillerato, } & \text { En Normal } \\ \text { Profesional } & \text { Superior. }\end{array}$

Técnico, Normal

Licenciatura, anterior a 1983 o especialización en Técnica Superior Maestría o la materia como actualización parte de la
a) Lectoescritura y literatura
b) Matemáticas
c) Ciencias
d) Estudios sociales
e) Lenguas extranjeras modernas
f) Griego antiguo o latín
g) Tecnología
h) Arte
i) Educación física
j) Religión o Ėtica
k) Habilidades técnicas o manuales
l) Materias interdisciplinares
m) Otra
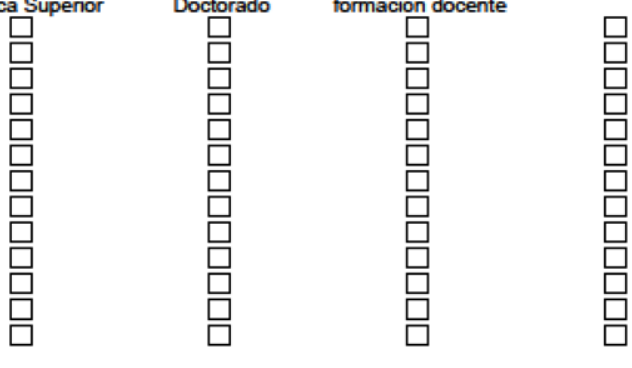

14) Durante este ciclo escolar, ¿enseña las siguientes materias?

a) Lectoescritura y literatura
b) Matemáticas
c) Ciencias
d) Estudios sociales
e) Lenguas extranjeras modernas
f) Griego antiguo o latín
g) Tecnología
h) Arte
i) Educación física
j) Religión o Ética
k) Habilidades técnicas o manuales
l) Materias interdisciplinares
m) Otra

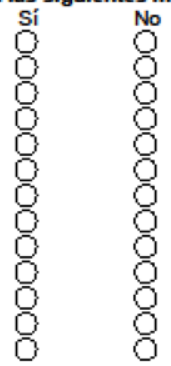

15) Durante la semana, ¿cuántas horas dedica a las siguientes actividades?:

a) Planeación individual o preparación de clase.

b) Trabajo en equipo y diálogo con otros docentes.

c) Revisión del trabajo de los estudiantes.

d) Consejería para alumnos (supervisión, asesoría virtual, prevención de delincuencia).

e) Participación en la dirección o gestión escolar.

f) Trabajo administrativo general (incluye comunicación, papelería u otras actividades de oficina).

g) Comunicación y cooperación con padres o tutores.

h) Actividades extracurriculares (p. ej.: actividades deportivas o culturales después de la escuela).

i) Otras actividades. 
16) Al iniciar su labor docente, ¿̇recibió inducción para docentes de nuevo ingreso?

a) Programa de inducción para docentes de nuevo ingreso.

b) Actividades de inducción informal para docentes.

c) Inducción general o administrativa para docentes de nuevo ingreso.

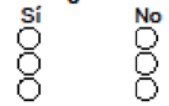

17) ¿Recibe o proporciona asesorias docentes?

a) Recibo asesoría técnico-pedagógica.

b) Asesoro a uno o más profesores.

$\begin{array}{ll}\text { Si } & \text { No } \\ \bigcirc & \bigcirc \\ 0 & \bigcirc\end{array}$

18) Durante los últimos 12 meses, ¿cuántos días participó en alguna de las siguientes actividades de desarrollo profesional?

Cursos o talleres

Congresos o seminarios sobre educación

Visitas de observación a otras escuelas

Visitas de observación a organizaciones públicas, privadas o no gubernamentales

Cursos de formación en el servicio de organizaciones públicas, privadas o no gubernamentales

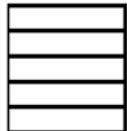

19) Durante los últimos 12 meses, ¿participó en alguna de las siguientes actividades?

Programa de cualificación (p. ej. programa para obtener un grado académico).

Participación en una red de docentes dedicada específicamente al desarrollo profesional. Investigación individual o colaborativa sobre un tema de su interés profesional.

Asesoría, observación o consejería de docentes, como una actividad formal de la escuela

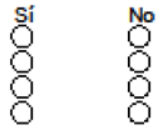

20) En las actividades de desarrollo profesional ¿se incluyeron los siguientes temas? si es así, ¿en qué medida impactaron en su labor docente?

a) Conocimiento y comprensión de las materias que enseño.

¿Se incluyeron
estos temas?

b) Competencias pedagógicas en la enseñanza de las materias que imparto.

c) Conocimiento del currículo (plan de estudios).

d) Prácticas de evaluación del estudiante.

e) Habilidades en el uso de las TIC (tecnologías de información y comunicación) para la enseñanza.

f) Comportamiento del estudiante y manejo del aula.

g) Gestión escolar y administración.

h) Enfoques al aprendizaje individualizado

i) Enseñanza a estudiantes con necesidades educativas especiales.

j) Enseñanza en un entorno multicultural o multilingūe.

k) Enseñanza de habilidades transversales (p. ej. solución de problemas, aprender a aprender).

l) Enfoques para el desarrollo de competencias laborales.

m) Nuevas tecnologías para el trabajo

n) Guía y consejería a estudiantes.

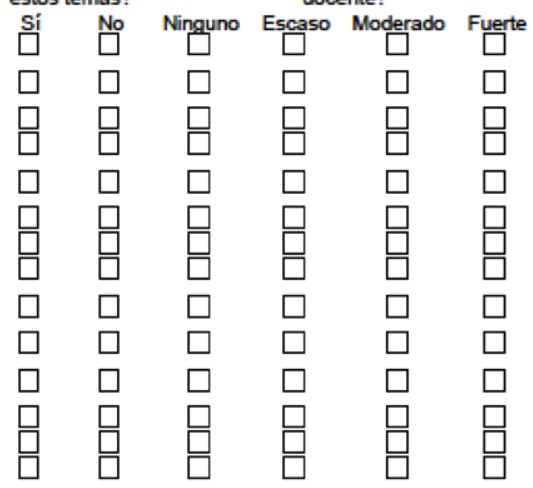

21) ¿Cuánto ha tenido que pagar (de su propio bolsillo) por las actividades de desarrollo profesional? Nada $O$ Una parte $\bigcirc$ Todo $\bigcirc$

22) ¿Ha recibido algún tipo de apoyo para las actividades de desarrollo profesional?

a) Tiempo para participar en las actividades que se llevaron a cabo en mi horario de trabajo.

b) Un complemento al salario para las actividades que se llevaron a cabo fuera del horario de trabajo.

c) Apoyo no monetario para las actividades fuera del horario de trabajo (menos horas de enseñanza, dias libres, faltas justificadas, etc.).

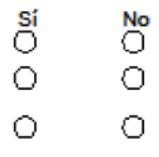


23) En qué medida las actividades de desarrollo profesional han integrado: No, en ninguna Si, en algunas actividad actividades

Si, en la mayoría de las actividades

Si, en todas las actividad actividades

a) Un grupo de compañeros de mi escuela o O<smiles>[O]</smiles><smiles>[O]</smiles>
b) Métodos de aprendizaje activo (no sólo escuchar un orador).

c) Aprendizaje colaborativo o investigación con otros profesores.

d) Un periodo de tiempo extenso (varias ocasiones a lo largo de varias semanas o meses).

0

(3)

G<smiles>[O]</smiles><smiles>[O]</smiles>

Q
(3)<smiles>[O]</smiles>

Q<smiles>[O]</smiles>

(3)<smiles>[O]</smiles><smiles>[O]</smiles>

O

\section{4) ¿En qué medida Usted necesita desarrollar los siguientes temas?}

a) Conocimiento y comprensión de las materias que enseño.

$\begin{array}{cc}\begin{array}{c}\text { Ninguna } \\ \text { necesidad }\end{array} & \begin{array}{c}\text { Necesidad } \\ \text { escasa }\end{array} \\ 0 & 0 \\ 0 & 0 \\ \square & 0 \\ 0 & 0 \\ 0 & 0 \\ 0 & 0 \\ 0 & 0 \\ \square & 0 \\ 0 & 0 \\ 0 & 0 \\ 0 & 0 \\ 0 & 0 \\ \square & 0\end{array}$
que imparto.

c) Conocimiento del currículo (plan de estudios).

d) Prácticas de evaluación del estudiante.

e) Habilidades en el uso de las TIC (tecnologías de información y comunicación) para la enseñanza.

f) Comportamiento del estudiante y manejo del aula.

g) Gestión escolar y administración.

h) Enfoques al aprendizaje individualizado

i) Enseñanza a estudiantes con necesidades educativas especiales.

j) Enseñanza en un entorno multicultural o multilingūe.

k) Enseñanza de habilidades transversales (p. ej. solución de problemas, aprender a aprender).

1) Enfoques para el desarrollo de competencias laborales.

m) Nuevas tecnologías para el trabajo

n) Guía y consejería a estudiantes escasa

D

0

0

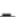

O

0

D

$\bigcirc$

$\bigcirc$

0

$\bigcirc$

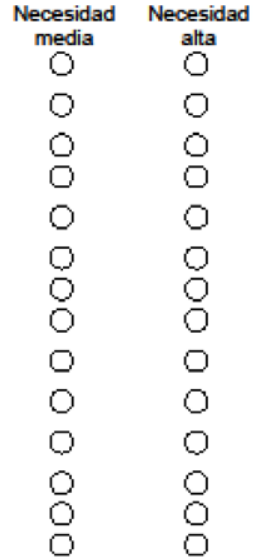

25) Seleccione los aspectos que obstaculizan su desarrollo profesional como docente: $\begin{array}{cc}\text { Totalmente en } & \text { En } \\ \text { desacuerdo } & \text { desacuerdo }\end{array}$

De Totalmente acuerdo de acuerdo

a) No cumplo con los requisitos necesarios (p. ej. titulación, $\mathrm{O}$

$\mathrm{O}$

0

b) El desarrollo profesional es muy costoso.

c) Falta apoyo de mis superiores.

d) El desarrollo profesional no se adecua con mi horario laboral.

e) No dispongo de tiempo debido a mis responsabilidades familiares.

f) No se ofrece desarrollo profesional relevante.

g) No hay incentivos para participar en este tipo de actividades

$\begin{array}{ll}0 & 0 \\ 0 & 0 \\ 0 & 0 \\ 0 & 0 \\ 0 & 0 \\ 0 & 0\end{array}$


26) En su escuela, ¿quiénes retroalimentan al docente en las siguientes actividades de evaluación?

\begin{tabular}{|c|c|c|c|c|c|}
\hline $\begin{array}{l}\text { Personas } \\
\text { externas }\end{array}$ & Director & $\begin{array}{c}\text { Otro } \\
\text { personal } \\
\text { directivo } \\
\text { en la } \\
\text { escuela }\end{array}$ & Asesores & $\begin{array}{l}\text { Otros } \\
\text { profesores } \\
\text { que no } \\
\text { son } \\
\text { directivos }\end{array}$ & $\begin{array}{c}\text { Nunca he } \\
\text { recibido esta } \\
\text { retro- } \\
\text { alimentación } \\
\text { en la escuela }\end{array}$ \\
\hline
\end{tabular}

a) Observación directa de la enseñanza

en el aula

b) Encuestas a los estudiantes sobre la enseñanza

c) Evaluación a los profesores sobre los contenidos de enseñanza

d) Análisis de los resultados de

evaluaciones de los estudiantes

e) Autoevaluaciones del trabajo de los profesores

f) Retroalimentación recibida por padres de familia

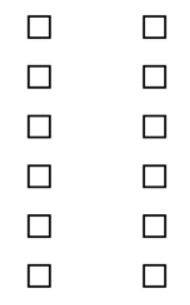

27) En relación a la evaluación docente, está Usted de acuerdo o en desacuerdo con lo siguiente:

a) Los docentes con mejor desempeño reciben mayor reconocimiento (p. ej. incentivos, capacitación o responsabilidades adicionales).

b) La evaluación y retroalimentación docente tiene poco impacto sobre la forma en que los docentes enseñan en el aula.

c) La evaluación y retroalimentación docente se realiza en gran medida para cumplir requisitos administrativos.

d) Existe un plan de desarrollo profesional establecido para mejorar el desempeño de los docentes.

e) Se brinda retroalimentación a los docentes con base en una exhaustiva evaluación de su enseñanza.

f) Si un docente presenta consistentemente un bajo desempeño. puede ser destituido de su escuela.

g) Se revisan con el docente las medidas para fortalecer las debilidades en la enseñanza.

h) Se designa un asesor para brindar apoyo en la mejora de la labor docente.

$\begin{array}{cr}\begin{array}{c}\text { Totalmente en } \\ \text { desacuerdo }\end{array} & \begin{array}{c}\text { En } \\ \text { desacuer }\end{array} \\ 0 & 0 \\ 0 & 0 \\ 0 & 0 \\ 0 & 0 \\ 0 & 0 \\ 0 & 0 \\ 0 & 0 \\ 0 & 0\end{array}$

28) En promedio, ¿con qué frecuencia realiza las siguientes actividades en su escuela?

\begin{tabular}{|c|c|c|c|c|c|c|}
\hline & Nunca & $\begin{array}{l}\text { Una vez al } \\
\text { año o } \\
\text { menos }\end{array}$ & $\begin{array}{l}\text { Entre } 2 \text { y } \\
4 \text { veces al } \\
\text { año }\end{array}$ & $\begin{array}{l}\text { Entre } 5 y \\
10 \text { veces al } \\
\text { año }\end{array}$ & $\begin{array}{l}\text { Entre } 1 \text { y } 3 \\
\text { veces al } \\
\text { mes }\end{array}$ & $\begin{array}{l}\text { Una vez a } \\
\text { la semana } \\
\text { o más }\end{array}$ \\
\hline $\begin{array}{l}\text { a) Enseñar conjuntamente con otros } \\
\text { docentes en la misma clase. }\end{array}$ & $\mathrm{O}$ & $\mathrm{O}$ & $\bigcirc$ & $\bigcirc$ & $\curvearrowright$ & $\Omega$ \\
\hline $\begin{array}{l}\text { b) Observar y retroalimentar las clases de } \\
\text { otros docentes. }\end{array}$ & 0 & 0 & 0 & 0 & 0 & 0 \\
\hline $\begin{array}{l}\text { c) Participar en actividades conjuntas con } \\
\text { diferentes clases o grupos de edad (p. ej. } \\
\text { proyectos). }\end{array}$ & 0 & 0 & 0 & 0 & 0 & 0 \\
\hline $\begin{array}{l}\text { d) Intercambiar materiales de enseñanza } \\
\text { con otros docentes. }\end{array}$ & $\bullet$ & 0 & $\square$ & 0 & 0 & $\bullet$ \\
\hline $\begin{array}{l}\text { e) Participar en conversaciones sobre el } \\
\text { desempeño de ciertos alumnos. }\end{array}$ & 0 & 0 & $Q$ & $Q$ & $Q$ & $Q$ \\
\hline $\begin{array}{l}\text { f) Trabajar con otros docentes de la } \\
\text { escuela para establecer estándares } \\
\text { comunes de evaluación del desempeño } \\
\text { de los estudiantes. }\end{array}$ & 0 & 0 & 0 & 0 & 0 & 0 \\
\hline $\begin{array}{l}\text { g) Asistir a reuniones del equipo de } \\
\text { trabajo. }\end{array}$ & 0 & 0 & 0 & 0 & 0 & 0 \\
\hline $\begin{array}{l}\text { h) Participar en actividades colaborativas } \\
\text { de aprendizaje profesional. }\end{array}$ & 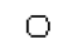 & 0 & 0 & $\square$ & 0 & 0 \\
\hline
\end{tabular}


29) ¿En qué medida está de acuerdo o en desacuerdo con las siguientes afirmaciones sobre su escuela?

$\begin{array}{cccc}\text { Totalmente en } & \text { En } & \text { De } & \text { Totalmente } \\ \text { desacuerdo desacuerdo acuerdo } & \text { de acuerdo }\end{array}$

a) La escuela brinda oportunidades para que el personal participe activamente en las decisiones.

b) La escuela brinda oportunidades para que los padres participen activamente en las decisiones.

c) La escuela brinda oportunidades para que los alumnos participen activamente en las decisiones.

d) La escuela tiene una cultura de responsabilidad compartida sobre los asuntos escolares.

e) Existe una cultura de colaboración en la escuela caracterizada por el apoyo mutuo.

30) En qué medida está de acuerdo o en desacuerdo con lo siguiente:

$$
\mathrm{O}
$$

a) Las ventajas de ser docente sobrepasan las desventajas.
b) Si pudiera decidir de nuevo escogeria trabajar como docente.
c) Quisiera cambiar de escuela, si fuera posible.
d) Me arrepiento de haber decidido ser docente.
e) Disfruto trabajar en esta escuela.
f) Me pregunto si hubiera sido mejor trabajar en otra profesión.
g) Recomendaría mi escuela como un buen lugar para trabajar.
h) Creo que la profesión docente está valorada en la sociedad.
i) Estoy satisfecho con mi desempeño en esta escuela.
j) En general, estoy satisfecho con mi labor docente.




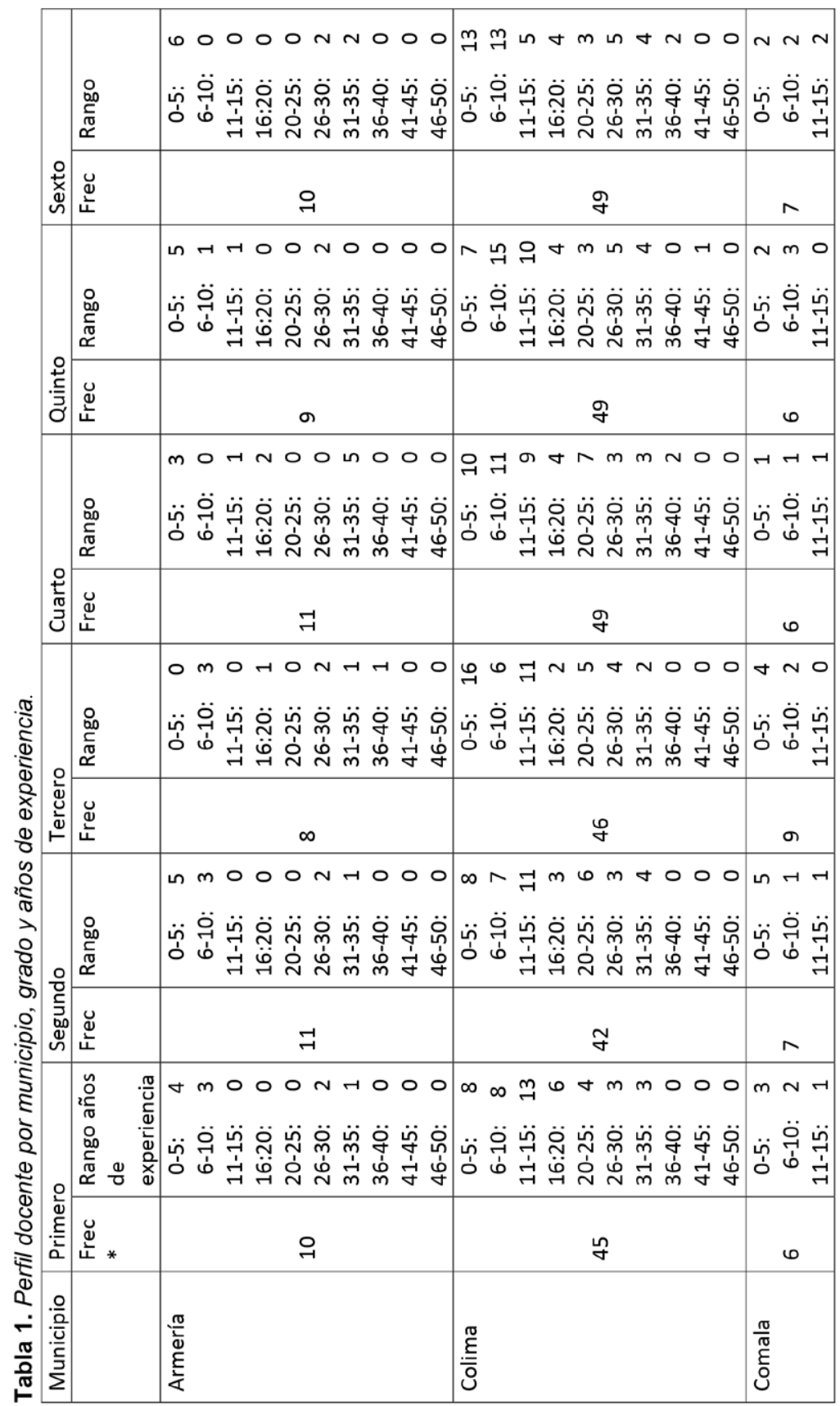




\begin{tabular}{|c|c|c|c|c|}
\hline & $\begin{array}{l}\text { 品 } \\
\underset{\pi}{\mathbb{\pi}} \\
\stackrel{\sim}{\simeq}\end{array}$ & 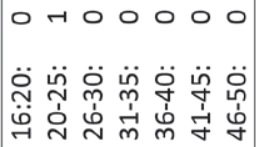 & 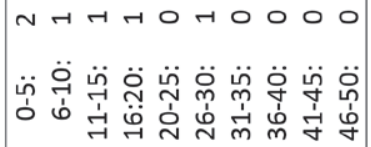 & 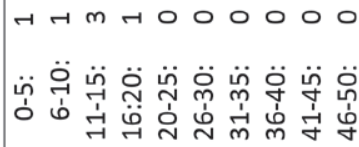 \\
\hline 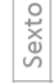 & 巡 & & 6 & 6 \\
\hline & 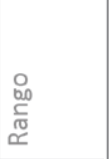 & 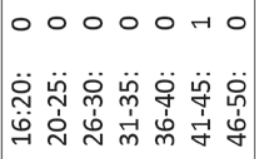 & 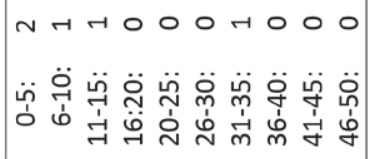 & 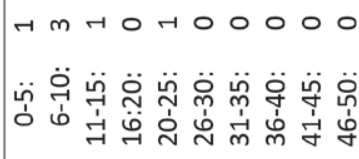 \\
\hline 言 & 巡 & & in & 0 \\
\hline & $\begin{array}{l}\text { 品 } \\
\underset{\mathbb{N}}{\mathbb{1}} \\
\simeq\end{array}$ & 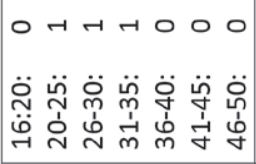 & 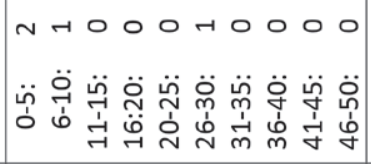 & 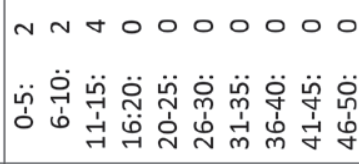 \\
\hline $\begin{array}{l}\frac{\pi}{\pi} \\
\frac{\pi}{3}\end{array}$ & 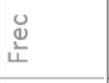 & & $\nabla$ & $\infty$ \\
\hline 0 & $\begin{array}{l}\text { 品 } \\
\underset{\mathbb{N}}{\mathbb{N}} \\
\simeq\end{array}$ & 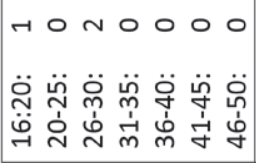 & 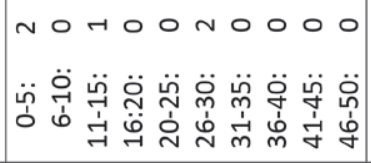 & 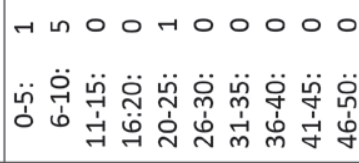 \\
\hline 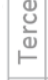 & $\begin{array}{l}\text { Uू } \\
\text { Lั }\end{array}$ & & in & $\wedge$ \\
\hline 음 & 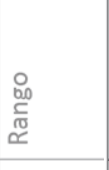 & 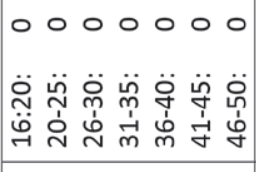 & 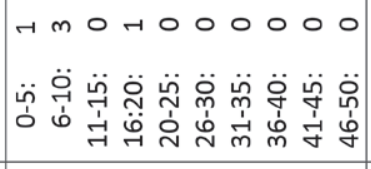 & 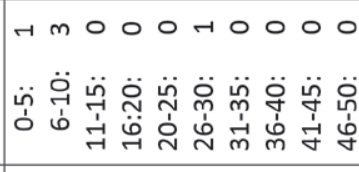 \\
\hline 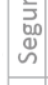 & 巡 & & in & in \\
\hline 은 & 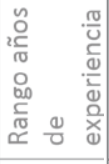 & 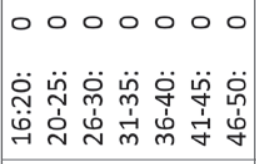 & 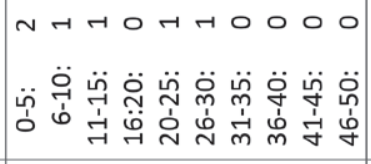 & 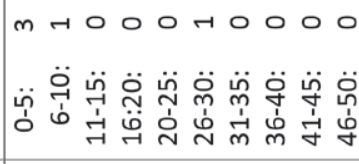 \\
\hline$\frac{\mathscr{E}}{\frac{\xi}{2}}$ & 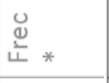 & & 6 & in \\
\hline$\frac{.0}{\frac{0}{\frac{3}{3}}}$ & & & 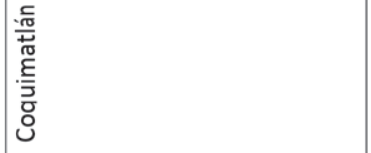 & 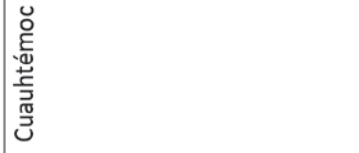 \\
\hline
\end{tabular}




\begin{tabular}{|c|c|c|c|c|}
\hline & $\begin{array}{l}\text { 品 } \\
\text { 市 } \\
\stackrel{1}{\simeq}\end{array}$ & 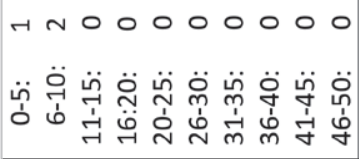 & 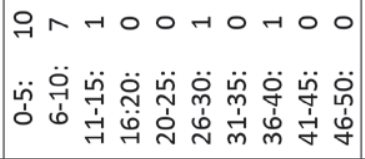 & 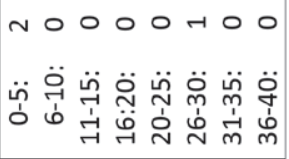 \\
\hline 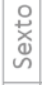 & 这 & $m$ & 유 & $m$ \\
\hline & $\begin{array}{l}\text { 品 } \\
\text { 茔 } \\
\simeq \simeq\end{array}$ & 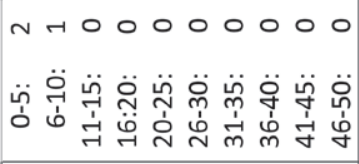 & 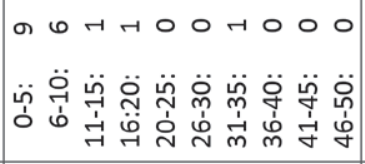 & 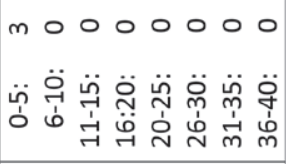 \\
\hline 童 & $\begin{array}{l}\text { d } \\
\text { 누 }\end{array}$ & $m$ & $\stackrel{\infty}{\rightarrow}$ & $m$ \\
\hline & $\begin{array}{l}\text { 品 } \\
\text { 茔 } \\
\stackrel{\complement}{\simeq}\end{array}$ & 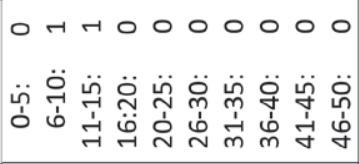 & 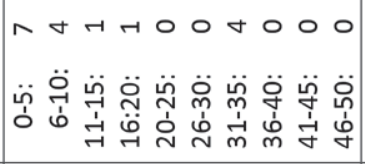 & 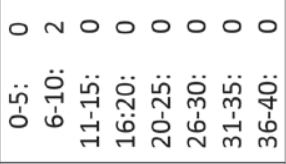 \\
\hline $\begin{array}{l}\frac{0}{t} \\
\frac{\pi}{3} \\
\end{array}$ & 巡 & $\sim$ & ન & $\sim$ \\
\hline o & 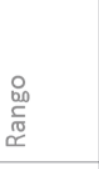 & 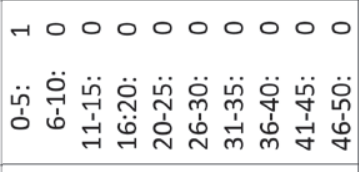 & 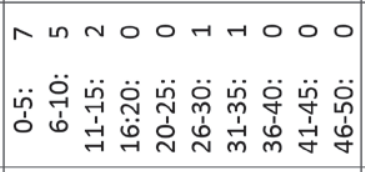 & 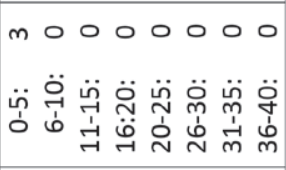 \\
\hline 选 & $\begin{array}{l}\text { d } \\
\text { 니 }\end{array}$ & $\rightarrow$ & $\stackrel{\leftrightarrow}{\sim}$ & $m$ \\
\hline 응 & 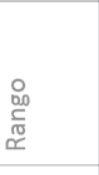 & 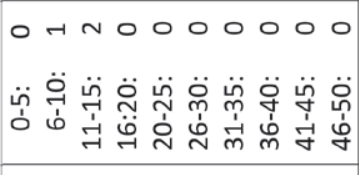 & 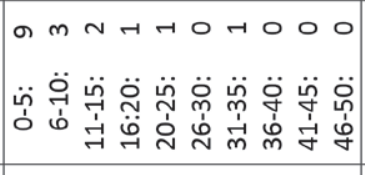 & 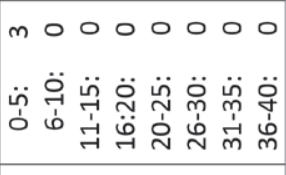 \\
\hline 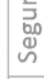 & 巡 & $m$ & ન & $m$ \\
\hline & 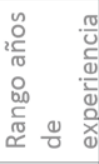 & 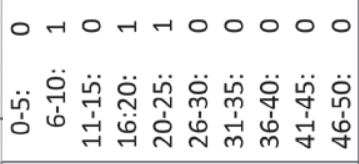 & 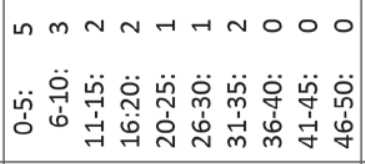 & 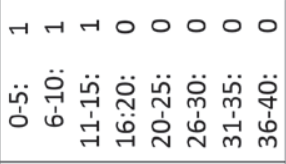 \\
\hline 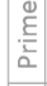 & 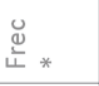 & $m$ & $\stackrel{\bullet}{\sim}$ & $m$ \\
\hline$\frac{\cdot \frac{0}{2}}{\frac{0}{\frac{0}{5}}}$ & & 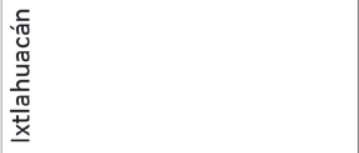 & 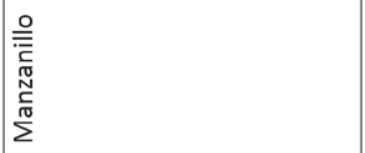 & 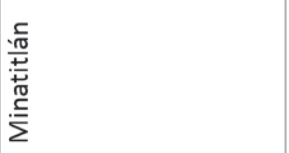 \\
\hline
\end{tabular}




\begin{tabular}{|c|c|c|c|c|}
\hline & 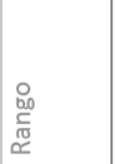 & 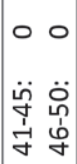 & 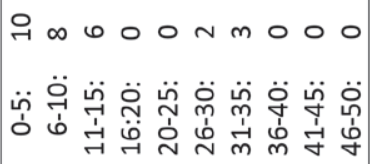 & 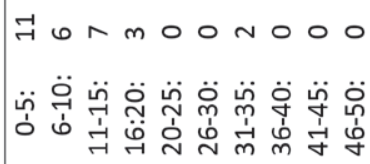 \\
\hline 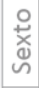 & 这 & & શ & ㄱ. \\
\hline & 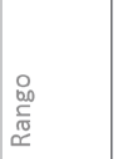 & 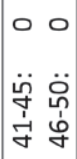 & 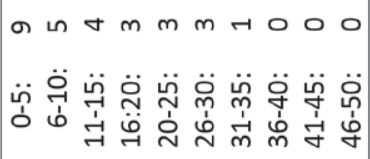 & 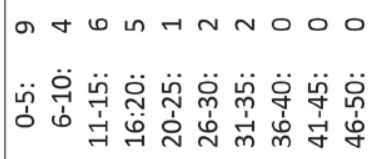 \\
\hline Oَّ & $\begin{array}{l}\text { U } \\
\text { 누 }\end{array}$ & & $\stackrel{\infty}{\sim}$ & ㄱ \\
\hline & 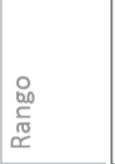 & $\begin{array}{ll}0 & 0 \\
\ddot{y} & 0 \\
y & 0 \\
\dot{1} & 0 \\
\dot{\gamma} & 0\end{array}$ & 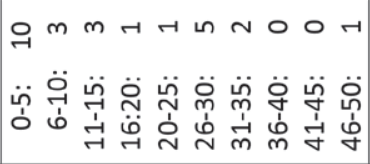 & 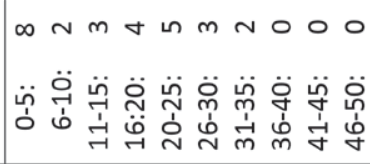 \\
\hline 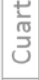 & 巡 & & $\ddot{N}$ & $\lesssim$ \\
\hline 운 & 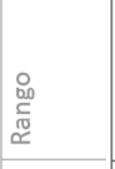 & 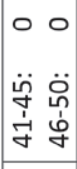 & 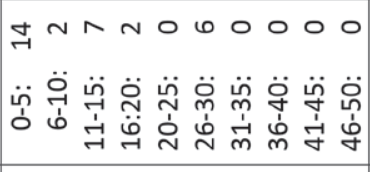 & 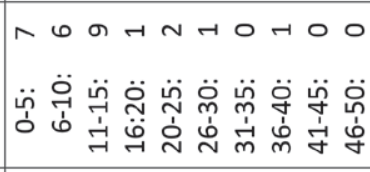 \\
\hline $\begin{array}{l}0 \\
0 \\
\stackrel{5}{0} \\
\vdash\end{array}$ & $\begin{array}{l}\text { U } \\
\text { 눈 }\end{array}$ & & $\vec{m}$ & $\hat{\sim}$ \\
\hline 웅 & 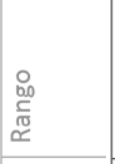 & 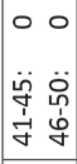 & 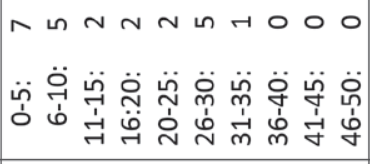 & 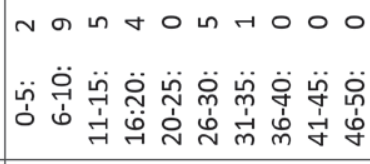 \\
\hline 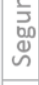 & 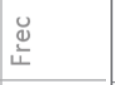 & & $\stackrel{d}{\sim}$ & $\ddot{N}$ \\
\hline 은 & 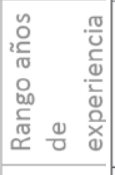 & 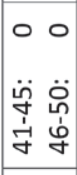 & 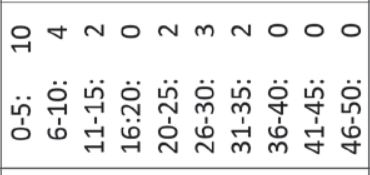 & 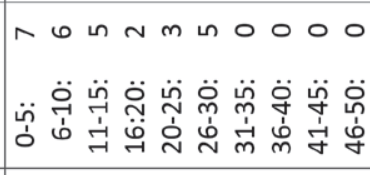 \\
\hline$\frac{E}{2}$ & $\begin{array}{l}\text { U } \\
\text { 누 * }\end{array}$ & & $\stackrel{m}{N}$ & $\stackrel{\infty}{\sim}$ \\
\hline$\frac{.0}{\frac{0}{3}}$ & & & 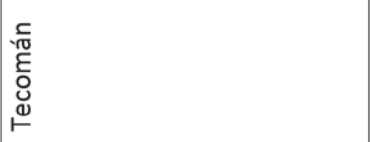 & 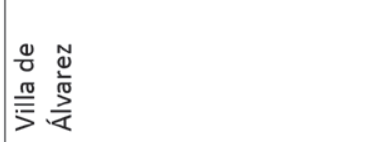 \\
\hline
\end{tabular}


Tabla 2. Porcentaje de docentes que han trabajado en una misma escuela con base en sus años de experiencia.

\begin{tabular}{lll}
\hline $\begin{array}{l}\text { Años } \\
\text { trabajando } \\
\text { en total }\end{array}$ & Cantidad de docentes & $\begin{array}{l}\text { Número de docentes que } \\
\text { llevan trabajando esa misma } \\
\text { cantidad de años en su } \\
\text { escuela }\end{array}$ \\
\hline $0-5$ & 272 & $108(39.7 \%)$ \\
$9-10$ & 191 & $12(6.3 \%)$ \\
$11-15$ & 127 & $1(0.8 \%)$ \\
$16-20$ & 54 & $1(1.9 \%)$ \\
$21-25$ & 47 & $2(4.3 \%)$ \\
$26-30$ & 87 & $1(1.1 \%)$ \\
$31-35$ & 51 & $0(0 \%)$ \\
$36-40$ & 7 & $0(0 \%)$ \\
$41-45$ & 2 & $0(0 \%)$ \\
$46-50$ & 1 & $0(0 \%)$ \\
\hline
\end{tabular}




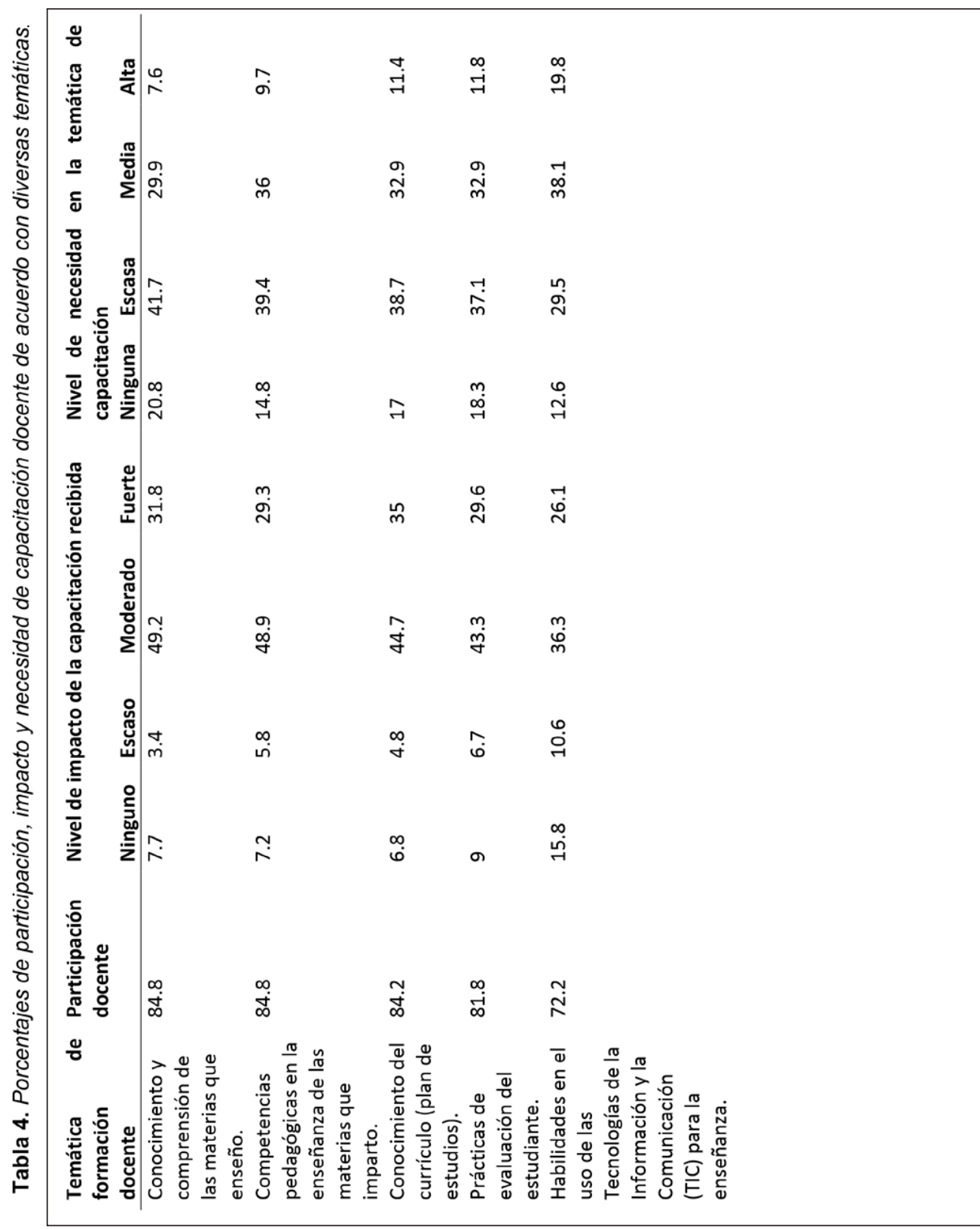




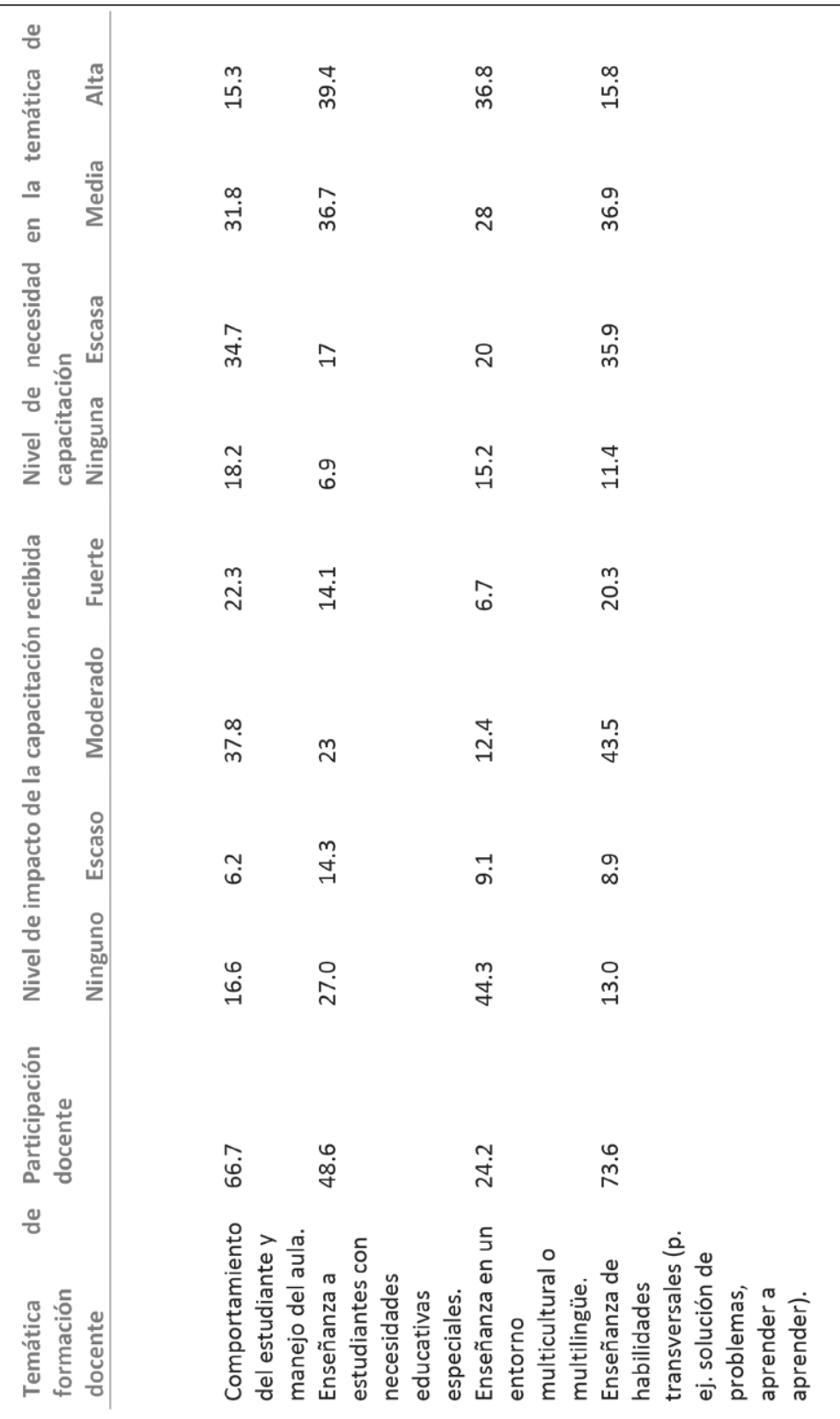




\section{REFERENCIAS}

Backhoff, E. y Pérez-Morán, J. C. (coords.) (2015). Segundo Estudio Internacional sobre la Enseñanza y el Aprendizaje (TALIS 2013). Resultados de México. México: INEE.

Banco Interamericano de Desarrollo [BID] (2011). Los docentes, las escuelas y los aprendizajes escolares en América Latina: Un estudio regional usando la base de datos del SERCE. División de Educación (SCL/EDU).

Barrera-Pedemonte, F. (2016). High-Quality Teacher Professional Development and Classroom Teaching Practices: Evidence from Talis 2013. Paris: Publicaciones OCDE. http://dx.doi.org/10.1787/ 5jlpszw26rvd-en

Bell, D. (1976). The coming of the post-industrial society. The Educational Forum, 40(4), 574-579. Taylor \& Francis Group.

Day, C. (1999). Developing teachers, the challenges of lifelong learning. The Falmer Press.UK. Recuperado de: http:/ / files.eric.ed. gov/fulltext/ED434878.pdf

Drucker, P. (1969). The age of discontinuity: Guidelines to our changing society. New York: Harper \& Row.

Secretaría de Educación Pública, SEP (2014). Resultados históricos nacionales 2006-2013. ENLACE 2013. Recuperado de: http:/ / www.enlace.sep.gob.mx/content/gr/docs/2013/ historico/00 EB 2013.pdf

Giroux, S. y Tremblay G. (2004). Metodología de las ciencias humanas. México: Fondo de Cultura Económica.

Hernández, R., Fernández-Collado, C., y Baptista, L. (2010). Metodología de la investigación. México, D.F.: McGrawHill. 
INEE (2015). Los docentes en México. Informe 2015. México: INEE.

Mendoza, J. L. y Roux, R. (2016). La investigación docente y el desarrollo profesional continuo: un estudio de caso en el noreste mexicano. Innovación Educativa, 16 (70), 43-60. ISSN: 1665-2673. Recuperado de: http://www.innovacion.ipn.mx/Revistas/ Documents / 2016/70/IE-70-3.pdf

OCDE (2004). La cuestión del profesorado: atraer, capacitar y conservar a profesores eficientes. Resumen en español. París. Recuperado de: http:/ / www.oecd.org/dataoecd/38/36/34991371.pdf

OCDE (2009a). Creating Effective Teaching and Learning Environments, First Results from TALIS. Recuperado de: http://www. oecd.org/dataoecd/17/51/43023606.pdf

OCDE (2009b). ¿Qué nos demostrará el TALIS en cuanto al desarrollo profesional de los maestros? Recuperado de: http://www. oecd.org/centrodemexico/encuestainternacionalsobredocencia yaprendizajetalis.htm\#1

OCDE, Teaching and Learning International Survey (TALIS) (2013). Reporte de resultados de TALIS 2013: figuras y tablas en Excel. Reporte recuperado de:

http://www.oecd.org/edu/school/talis-excel-figures-and-tables. $\underline{\mathrm{htm}}$

OCDE (2014). Talis 2013 Results: An International Perspective on Teaching and Learning. OECD Publishing. http:/ / dx.doi.org/10.1787/9789264196261-en

Schleicher, A. (2009). El informe TALIS. Conclusiones de la Primera Evaluación Internacional sobre Enseñanza y Aprendizaje. Fundación Santillana. Recuperado de:

http:/ / www.fundacionsantillana.com/upload/ficheros/noticias/ 200911/interior_db_maquetado_2009_1.pdf 
Vezub, L. F. (2007). La formación y el desarrollo profesional docente frente a los nuevos desafíos de la escolaridad. Profesorado Revista de currículum y formación del profesorado, 11(1), 1-23. Recuperado de: http:/ / digibug.ugr.es/bitstream/10481/17485/1/ rev111ART2.pdf

Villegas-Reimers, E. (2003). Teacher professional development: an international review of the literature. UNESCO: IIEP. Recuperado de: http: / / unesdoc.unesco.org/images/0013/001330/133010e.pdf. 